\title{
Target of Triglycerides as Residual Risk for Cardiovascular Events in Patients With Coronary Artery Disease - Post Hoc Analysis of the FMD-J Study A -
}

Masato Kajikawa, MD, PhD; Tatsuya Maruhashi, MD, PhD; Shinji Kishimoto, MD; Shogo Matsui, MD; Haruki Hashimoto, MD; Yuji Takaeko, MD; Farina Mohamad Yusoff, MD;

Yasuki Kihara, MD, PhD; Kazuaki Chayama, MD, PhD; Chikara Goto, PhD; Kensuke Noma, MD, PhD; Ayumu Nakashima, MD, PhD; Hirofumi Tomiyama, MD, PhD; Bonpei Takase, MD, PhD; Takahide Kohro, MD, PhD; Toru Suzuki, MD, PhD; Tomoko Ishizu, MD, PhD; Shinichiro Ueda, MD, PhD; Tsutomu Yamazaki, MD, PhD;

Tomoo Furumoto, MD, PhD; Kazuomi Kario, MD, PhD; Teruo Inoue, MD, PhD; Shinji Koba, MD, PhD; Kentaro Watanabe, MD, PhD; Yasuhiko Takemoto, MD, PhD;

Takuzo Hano, MD, PhD; Masataka Sata, MD, PhD; Yutaka Ishibashi, MD, PhD; Koichi Node, MD, PhD; Koji Maemura, MD, PhD; Yusuke Ohya, MD, PhD; Taiji Furukawa, MD, PhD; Hiroshi Ito, MD, PhD; Hisao Ikeda, MD, PhD; Akira Yamashina, MD, PhD; Yukihito Higashi, MD, PhD

\begin{abstract}
Background: Circulating triglyceride (TG) levels are a current focus as a residual risk for cardiovascular (CV) events. We evaluated the relationship between circulating TG levels and future CV events in patients with coronary artery disease (CAD) who were treated with conventional therapy.

Methods and Results: We analyzed data for 652 patients who were enrolled in the FMD-J Study A. We investigated the associations between serum TG levels and first major CV events (death from CV cause, nonfatal acute coronary syndrome (ACS), nonfatal stroke, and CAD) for a 3-year follow-up period. Patients were divided into 4 groups based on serum TG level: low-normal (<100mg/dL), high-normal (100-149 mg/dL), borderline hypertriglyceridemia (150-199 mg/dL), and moderate hypertriglyceridemia ( $\geq 200 \mathrm{mg} / \mathrm{dL})$. During a median follow-up period of 46.6 months, 14 patients died ( 9 from CV causes), 16 had nonfatal ACS, 6 had nonfatal stroke, and 54 had CAD. The Kaplan-Meier curves for first major CV event among the 4 groups were significantly different $(P=0.04)$. After adjustment for various confounders, serum TG level $\geq 100 \mathrm{mg} / \mathrm{dL}$ were significantly associated with an increased risk of first major CV events compared with serum TG level $<100 \mathrm{mg} / \mathrm{dL}$.
\end{abstract}

Conclusions: Serum TG level may be a surrogate marker for predicting CV events in patients with CAD.

Key Words: Atherosclerosis; Cardiovascular events; Triglycerides

A n elevated serum level of low-density lipoprotein cholesterol (LDL-C) is an independent risk factor for cardiovascular $(\mathrm{CV})$ disease. ${ }^{1-4}$ Although the benefits of LDL-C lowering on CV events are well established, patients with dyslipidemia still have a high residual

\section{Editorial p 969}

risk of such events. ${ }^{\mathbf{5}, \mathbf{6}}$ Several lines of evidence have shown a link between serum triglyceride (TG) levels and CV dis-

Received November 20, 2018; revised manuscript received February 5, 2019; accepted February 12, 2019; J-STAGE Advance Publication released online March 26, 2019 Time for primary review: 34 days

Division of Regeneration and Medicine, Medical Center for Translational and Clinical Research, Hiroshima University Hospital, Hiroshima (M.K., K. Noma, A.N., Y.H.); Department of Cardiovascular Medicine, Graduate School of Biomedical and Health Sciences (T.M., S.M., H.H., Y.T., Y.K.), Department of Cardiovascular Regeneration and Medicine, Research Institute for Radiation Biology and Medicine (S. Kishimoto, F.M.Y., K. Noma, Y.H.), Department of Gastroenterology and Metabolism, Institute of Biomedical and Health Sciences, Graduate School of Biomedical and Health Sciences (K.C.), Hiroshima University, Hiroshima; Department of Physical Therapy, Hiroshima International University, Hiroshima (C.G.); Department of Cardiology, Tokyo Medical University, Tokyo (H.T., A.Y.); Division of Biomedical Engineering, National Defense Medical College Research Institute, Tokorozawa (B.T.); Department of Clinical Informatics (T.K.), Division of Cardiovascular Medicine (K.K.), Jichi Medical University School of Medicine, Tochigi, Japan; Cardiovascular Medicine, University of Leicester, Leicester (T.S.), UK;

(Footnote continued the next page.) 
ease. ${ }^{5}$ However, there are conflicting results regarding the association between elevated serum TG levels and the incidence of $\mathrm{CV}$ events. ${ }^{5-12}$

In the guidelines for cholesterol management, serum TG levels $<150 \mathrm{mg} / \mathrm{dL}$ are defined as normal. ${ }^{\mathbf{1 2 , 9}}$ Some clinical studies have shown that reducing TG levels by treatment with fibrates reduces $\mathrm{CV}$ events in a subgroup of patients with high TG levels. ${ }^{13,14}$ Unfortunately, there is insufficient evidence available to determine optimal TG levels for prevention of $\mathrm{CV}$ events. Klempfner et al reported that highnormal TG levels $(100-150 \mathrm{mg} / \mathrm{dL})$ are associated with an increased risk of all-cause death. ${ }^{15} \mathrm{We}$ previously showed that endothelial function is already impaired even in subjects with serum TG levels of $106-131 \mathrm{mg} / \mathrm{dL}$ after adjustment for various confounders. ${ }^{16}$ However, it is unclear whether patients with high-normal TG levels have an increased risk of $\mathrm{CV}$ events. The purpose of this study was to evaluate the relationship between circulating TG levels, especially high-normal TG levels, and future CV events in patients with coronary artery disease (CAD) who were treated with conventional therapy including LDL-C lowering treatment.

\section{Methods}

\section{Study Design}

The rationale and design of the FMD-J Study A have been described previously. ${ }^{17}, 18$ It was a prospective multicenter observational cohort study conducted at 22 university hospitals and affiliated clinics in Japan to examine the usefulness of flow-mediated vasodilation assessment for the management of patients with CAD with a 3-year follow-up period. ${ }^{17,18}$ The study was approved by the ethical committee of each institute and was executed in accordance with the Good Clinical Practice guidelines. All subjects gave written informed consent for participation in the study. The protocol was registered in the University Hospital Medical Information Network Clinical Trials Registry (UMIN000012950).

\section{Study Subjects}

Between May 1, 2010 and August 31, 2012, a total of 679 patients aged $30-88$ years who had been diagnosed with CAD were enrolled in the FMD-J Study A. CAD was defined as myocardial infarction, angina pectoris with organic stenosis of at least 1 coronary artery confirmed by diagnostic imaging (coronary angiography, cardiac nuclear scintigraphy, or coronary computed tomography), or previous percutaneous coronary intervention. The exclusion criteria were as follows: a history of coronary bypass surgery; severe valvular heart disease; arrhythmia that required treatment (i.e., atrial fibrillation, atrial flutter; permanent pacemaker implantation or frequent ventricular premature beats); severe chronic heart failure (New York Heart Association level > Level III); malignancy; undergoing treatment with steroids, nonsteroidal anti-inflammatory drugs, or immunosuppressive drugs; a serum creatinine level $>2.5 \mathrm{mg} / \mathrm{dL}$; a history of stroke, aortic disease (except peripheral artery disease), or serious liver disease; and judgement of the attending physician that the individual was ineligible for inclusion in the study.

\section{Study Procedures}

Blood examinations were conducted at the start of the study and CV events were monitored annually during the 3-year follow-up period. The participants were managed by their attending physicians, who were encouraged to treat any CV risk factors, including hypertension, dyslipidemia and diabetes mellitus, to achieve the best available standard of care in accordance with guidelines. ${ }^{1,3,4,19-21}$

\section{Measurement of Blood Samples and Assessment of CV Risk Factors}

The subjects were instructed to abstain from eating, drinking alcohol, smoking and consuming caffeine for at least $12 \mathrm{~h}$ prior to the study. Venous blood samples were obtained from the left antecubital vein. Levels of serum total cholesterol, TGs, and high-density lipoprotein cholesterol (HDLC) were enzymatically measured (JCA-BM6010). LDL-C was calculated by the Friedewald formula. We excluded patients with serum TG levels $\geq 400 \mathrm{mg} / \mathrm{dL}$. Non-HDL-C was calculated by the following formula: total cholesterol - HDL-C. Small dense LDL-C (sdLDL-C) was measured by the method previously described.22 Glucose levels were measured by the glucose oxidase immobilized oxygen electrode method (GA08II; A\&T, Yokohama, Japan). Hypertension was defined as systolic blood pressure $\geq 140 \mathrm{mmHg}$ or diastolic blood pressure $\geq 90 \mathrm{mmHg}$ on at least 3 different occasions in a seated position, or currently taking antihypertensive medication. ${ }^{20}$ Diabetes mellitus was identified

Cardiovascular Division, Institute of Clinical Medicine, University of Tsukuba, Ibaraki (T. Ishizu); Department of Clinical Pharmacology and Therapeutics, University of the Ryukyu School of Medicine, Okinawa (S.U.); Department of Clinical Epidemiology and Systems, Faculty of Medicine, The University of Tokyo, Tokyo (T.Y.); Department of Cardiovascular Medicine, Hokkaido University Graduate School of Medicine, Hokkaido (T. Furumoto); Department of Cardiovascular Medicine, Dokkyo Medical University, Tochigi (T. Inoue); Department of Medicine, Division of Cardiology, Showa University School of Medicine, Tokyo (S. Koba); Department of Neurology, Hematology, Metabolism, Endocrinology and Diabetology (DNHMED), Yamagata University School of Medicine, Yamagata (K.W.); Department of Internal Medicine and Cardiology, Osaka City University Graduate School of Medicine, Osaka (Y. Takemoto); Department of Medical Education and Population-based Medicine, Postgraduate School of Medicine, Wakayama Medical University, Wakayama (T.H.); Department of Cardiovascular Medicine, Institute of Health Biosciences, The University of Tokushima Graduate School, Tokushima (M.S.); Department of General Medicine, Shimane University Faculty of Medicine, Shimane (Y.I.); Department of Cardiovascular and Renal Medicine, Saga University, Saga (K. Node); Department of Cardiovascular Medicine, Course of Medical and Dental Sciences, Graduate School of Biomedical Sciences, Nagasaki University, Nagasaki (K.M.); The Third Department of Internal Medicine, University of the Ryukyus, Okinawa (Y.O.); Department of Internal Medicine, Teikyo University School of Medicine, Tokyo (T. Furukawa); Department of Cardiovascular Medicine, Okayama University Graduate School of Medicine, Dentistry and Pharmaceutical Sciences, Okayama (H. Ito); and Faculty of Fukuoka Medical Technology, Teikyo University, Fukuoka (H. Ikeda), Japan

Mailing address: Yukihito Higashi, MD, PhD, FAHA, Department of Cardiovascular Regeneration and Medicine, Research Institute for Radiation Biology and Medicine (RIRBM), Hiroshima University, 1-2-3 Kasumi, Minami-ku, Hiroshima 734-8551, Japan. E-mail: yhigashi@hiroshima-u.ac.jp

ISSN-1346-9843 All rights are reserved to the Japanese Circulation Society. For permissions, please e-mail: cj@j-circ.or.jp 


\begin{tabular}{|c|c|c|c|c|c|c|}
\hline Variable & $\begin{array}{c}\text { Total } \\
(n=652)\end{array}$ & $\begin{array}{c}<100 \\
(n=264)\end{array}$ & $\begin{array}{l}100-149 \\
(n=188)\end{array}$ & $\begin{array}{l}150-199 \\
(n=104)\end{array}$ & $\begin{array}{l}\geq 200 \\
(\mathrm{n}=96)\end{array}$ & $\begin{array}{l}\text { P value } \\
\text { for trend }\end{array}$ \\
\hline Age, years & $64 \pm 8$ & $66 \pm 8$ & $64 \pm 9$ & $62 \pm 9$ & $62 \pm 8$ & $<0.001$ \\
\hline Sex, male/female & $545 / 107$ & $216 / 48$ & $156 / 32$ & $88 / 16$ & $85 / 11$ & 0.46 \\
\hline BMI, $\mathbf{k g} / \mathrm{m}^{2}$ & $24.8 \pm 3.6$ & $24.0 \pm 3.6$ & $25.1 \pm 3.5$ & $25.5 \pm 4.0$ & $25.8 \pm 3.1$ & $<0.001$ \\
\hline SBP, mmHg & $129 \pm 17$ & $129 \pm 17$ & $131 \pm 17$ & $129 \pm 16$ & $128 \pm 16$ & 0.53 \\
\hline DBP, $\mathrm{mmHg}$ & $75 \pm 11$ & $74 \pm 11$ & $76 \pm 11$ & $75 \pm 10$ & $74 \pm 11$ & 0.23 \\
\hline Heart rate, beats/min & $67 \pm 12$ & $66 \pm 11$ & $67 \pm 12$ & $66 \pm 11$ & $68 \pm 14$ & 0.52 \\
\hline \multicolumn{7}{|l|}{ Medical history, n (\%) } \\
\hline Hypertension & $613(94)$ & $243(92)$ & $180(96)$ & $102(98)$ & $88(92)$ & 0.053 \\
\hline Dyslipidemia & $610(94)$ & $232(88)$ & $178(95)$ & $104(100)$ & $96(100)$ & $<0.001$ \\
\hline Diabetes mellitus & $243(37)$ & $100(38)$ & $66(35)$ & $38(37)$ & $39(41)$ & 0.82 \\
\hline Smoker & $87(14)$ & $26(10)$ & $28(15)$ & $14(14)$ & $19(20)$ & 0.08 \\
\hline Previous MI & $308(47)$ & $116(44)$ & $94(50)$ & $48(46)$ & $50(52)$ & 0.44 \\
\hline Previous angina pectoris & $333(51)$ & $142(54)$ & $91(48)$ & $56(54)$ & $44(46)$ & 0.44 \\
\hline Vasospastic angina & $31(5)$ & $14(5)$ & $10(5)$ & $3(3)$ & $4(4)$ & 0.73 \\
\hline \multicolumn{7}{|l|}{ Laboratory data } \\
\hline Total cholesterol, mg/dL & $170 \pm 30$ & $164 \pm 27$ & $166 \pm 33$ & $177 \pm 30$ & $182 \pm 31$ & $<0.001$ \\
\hline Triglycerides, mg/dL & $131 \pm 66$ & $75 \pm 16$ & $122 \pm 14$ & $171 \pm 13$ & $256 \pm 47$ & $<0.001$ \\
\hline $\mathrm{HDL}-\mathrm{C}, \mathrm{mg} / \mathrm{dL}$ & $51 \pm 13$ & $56 \pm 14$ & $48 \pm 11$ & $47 \pm 12$ & $43 \pm 10$ & $<0.001$ \\
\hline LDL-C, mg/dL & $93 \pm 27$ & $93 \pm 23$ & $94 \pm 30$ & $96 \pm 28$ & $87 \pm 30$ & 0.11 \\
\hline sdLDL-C, mg/dL & $33 \pm 14$ & $25 \pm 9$ & $31 \pm 11$ & $41 \pm 15$ & $48 \pm 13$ & $<0.001$ \\
\hline Ratio of sdLDL-C to LDL-C & $0.36 \pm 0.15$ & $0.27 \pm 0.07$ & $0.34 \pm 0.10$ & $0.44 \pm 0.12$ & $0.56 \pm 0.17$ & $<0.001$ \\
\hline Non-HDL-C, mg/dL & $119 \pm 29$ & $108 \pm 24$ & $119 \pm 30$ & $130 \pm 28$ & $138 \pm 28$ & $<0.001$ \\
\hline Glucose, mg/dL & $117 \pm 35$ & $114 \pm 29$ & $115 \pm 29$ & $119 \pm 37$ & $127 \pm 50$ & 0.01 \\
\hline $\mathrm{HbA} 1 \mathrm{c}, \%$ & $6.4 \pm 1.0$ & $6.3 \pm 0.9$ & $6.4 \pm 1.0$ & $6.5 \pm 1.2$ & $6.7 \pm 1.2$ & 0.15 \\
\hline High-sensitivity CRP, mg/dL & $0.10 \pm 0.14$ & $0.09 \pm 0.14$ & $0.11 \pm 0.16$ & $0.09 \pm 0.10$ & $0.12 \pm 0.15$ & 0.24 \\
\hline \multicolumn{7}{|l|}{ Medications, n (\%) } \\
\hline Antiplatelets & $620(95)$ & $252(95)$ & $176(94)$ & $98(94)$ & $94(98)$ & 0.37 \\
\hline Antihypertensive therapy & $600(92)$ & $239(91)$ & $176(94)$ & $98(94)$ & $87(91)$ & 0.48 \\
\hline Calcium-channel blockers & $317(49)$ & $125(47)$ & $97(52)$ & $58(56)$ & $37(39)$ & 0.07 \\
\hline Renin-angiotensin system inhibitors & $443(68)$ & $169(64)$ & $132(70)$ & $72(69)$ & $70(73)$ & 0.32 \\
\hline$\beta$-blockers & $292(45)$ & $117(44)$ & $83(44)$ & $48(46)$ & $44(46)$ & 0.98 \\
\hline Diuretics & $77(12)$ & $33(13)$ & $24(13)$ & $11(11)$ & $9(9)$ & 0.80 \\
\hline Any lipid modification therapy & $577(88)$ & $228(86)$ & $172(91)$ & $92(88)$ & $85(89)$ & 0.40 \\
\hline Statins & $541(83)$ & $214(81)$ & $159(85)$ & $88(85)$ & $80(83)$ & 0.75 \\
\hline Fibrates & $13(2)$ & $7(3)$ & $3(2)$ & $2(2)$ & $1(1)$ & 0.74 \\
\hline Eicosapentaenoic acids & $42(6)$ & $15(6)$ & $19(10)$ & $5(5)$ & $3(3)$ & 0.09 \\
\hline Ezetimibe & $46(7)$ & $22(8)$ & $10(5)$ & $5(5)$ & $9(9)$ & 0.37 \\
\hline \multicolumn{7}{|l|}{ Antihyperglycemic therapy } \\
\hline Any & $199(31)$ & $82(31)$ & $58(31)$ & $32(31)$ & $27(28)$ & 0.96 \\
\hline Insulin-dependent & $38(6)$ & $18(7)$ & $14(7)$ & $3(3)$ & $3(3)$ & 0.19 \\
\hline Framingham risk score, $\%$ & $12.4 \pm 7.5$ & $10.9 \pm 6.4$ & $12.7 \pm 8.3$ & $12.8 \pm 7.7$ & $15.6 \pm 7.4$ & $<0.001$ \\
\hline FMD, \% & $4.7 \pm 2.8$ & $4.5 \pm 2.8$ & $4.6 \pm 2.5$ & $4.9 \pm 2.8$ & $5.1 \pm 3.4$ & 0.26 \\
\hline
\end{tabular}

All results are presented as mean \pm SD. BMI, body mass index; CRP, C-reactive protein; DBP, diastolic blood pressure; FMD, flow-mediated vasodilation; HDL-C, high-density lipoprotein cholesterol; LDL-C, low-density lipoprotein cholesterol; MI, myocardial infarction; SBP, systolic blood pressure; sdLDL-C, small dense low-density lipoprotein cholesterol.

using the American Diabetes Association criteria. ${ }^{23}$ Dyslipidemia was identified using the Third Report of the National Cholesterol Education Program. ${ }^{2}$ We defined smokers as those who were current smokers. The Framingham risk score was calculated by points of risk factors: age, total cholesterol level, HDL-C level, systolic blood pressure, and smoking status. ${ }^{24}$

\section{Measurement of Flow-Mediated Dilation (FMD)}

A high-resolution ultrasonography (UNEXEF18G, UNEX
Co, Nagoya, Japan) was used to evaluate FMD. The protocol for measurement of FMD has been described in detail. ${ }^{25}$ Briefly, the longitudinal image of the brachial artery was assessed before and after generation of a vascular response to reactive hyperemia induced by a 5 -min period of forearm occlusion to evaluate FMD. FMD was defined as the maximal percentage change in vessel diameter from the baseline value. 


\section{Outcomes}

All CV events were reported annually from each institution to the Efficacy Endpoint Review Committee. An independent clinical-events committee adjudicated the endpoints of death from CV causes, nonfatal acute coronary syndrome (ACS), nonfatal stroke, CAD, hospitalization for heart failure, and death from any cause. ${ }^{17,18} \mathrm{CAD}$ was defined as coronary artery restenosis or de novo coronary artery stenosis, confirmed by diagnostic imaging (coronary angiography, cardiac nuclear scintigraphy, or coronary computed tomography). Definitions of the clinical outcomes have been provided previously. ${ }^{17,18}$ The committee, consisting of members blinded to any information with regard to blood samples, assessed the appropriateness of clinical judgements of $\mathrm{CV}$ events according to prespecified criteria. The committee could request physicians to provide additional clinical information on CV events if needed. Any differences in opinion under assessment were resolved by discussion, and the committee finally determined whether the CV event would be included as an outcome event in the analysis. We first assessed the associations of serum TG levels with first major $\mathrm{CV}$ event (death from $\mathrm{CV}$ cause, nonfatal ACS, nonfatal stroke, and CAD) and then we assessed the associations with death from CV causes, nonfatal ACS, nonfatal stroke, CAD, hospitalization for heart failure, and death from any cause.

\section{Statistical Analysis}

Results are presented as mean $\pm \mathrm{SD}$ for continuous variables and as percentages for categorical variables. Statistical significance was set at a level of $\mathrm{P}<0.05$. Continuous variables were compared by using ANOVA for multiple groups. Categorical variables were compared by means of the $\chi^{2}$ test. Relations between variables were determined by Pearson's correlation analysis. Time-to-event endpoint analyses were performed by the Kaplan-Meier method. We categorized subjects into 4 groups according to the serum TG level: lownormal $(<100 \mathrm{mg} / \mathrm{dL})$, high-normal $(100-149 \mathrm{mg} / \mathrm{dL})$, borderline hypertriglyceridemia $(150-199 \mathrm{mg} / \mathrm{dL})$, moderate hypertriglyceridemia $(\geq 200 \mathrm{mg} / \mathrm{dL}) .{ }^{9}$ A log-rank test was used to compare survival in the groups. We evaluated the associations between serum TG levels and first major CV events after adjustment for age, sex, and CV risk factors by using Cox's proportional hazard regression analysis. As the sensitivity analysis, we performed exploratory analysis to evaluate the prognostic value of serum TG levels before and after adjustment for age and sex. In the second sensitivity analysis, the proportional hazards assumption was confirmed by inspection of Schoenfeld residuals and log-log plotting. The data was processed using the software package Stata version 9 (Stata Co., College Station, TX, USA).

\section{Results}

\section{Baseline Clinical Characteristics}

Of the 679 patients, complete outcome data were available for 652 and their baseline characteristics are summarized in Table 1. Of the 652 patients, $545(84 \%)$ were men and 107 $(16 \%)$ were women. Mean levels of total cholesterol, TGs, HDL-C, and LDL-C were $170 \pm 30 \mathrm{mg} / \mathrm{dL}, 131 \pm 66 \mathrm{mg} / \mathrm{dL}$, $51 \pm 13 \mathrm{mg} / \mathrm{dL}$, and $93 \pm 27 \mathrm{mg} / \mathrm{dL}$, respectively. Of the 652 patients, $613(94 \%)$ had hypertension, $610(94 \%)$ had dyslipidemia, $243(37 \%)$ had diabetes mellitus, and $87(14 \%)$ were current smokers. Among the patients, $577(88 \%)$ were being treated with lipid-lowering agents, and $541(83 \%)$ of

\begin{tabular}{|lcc|}
\hline \multicolumn{3}{|c|}{ Table 2. Univariate Analysis of Relationships Between } \\
Serum Triglyceride Levels and Variables \\
Variables & $\mathbf{r}$ & P value \\
Age, years & -0.18 & $<0.001$ \\
$\mathrm{BMI}, \mathrm{kg} / \mathrm{m}^{2}$ & 0.20 & $<0.001$ \\
$\mathrm{SBP}, \mathrm{mmHg}$ & -0.03 & 0.44 \\
DBP, $\mathrm{mmHg}$ & 0.03 & 0.50 \\
Heart rate, beats/min & 0.04 & 0.27 \\
Total cholesterol, mg/dL & 0.21 & $<0.001$ \\
HDL-C, mg/dL & -0.37 & $<0.001$ \\
LDL-C, mg/dL & -0.07 & 0.09 \\
sdLDL-C, mg/dL & 0.60 & $<0.001$ \\
Ratio of sdLDL-C to LDL-C & 0.71 & $<0.001$ \\
Non-HDL-C, mg/dL & 0.39 & $<0.001$ \\
Glucose, mg/dL & 0.14 & $<0.001$ \\
HbA1c, \% & 0.10 & 0.04 \\
High-sensitivity CRP, mg/dL & 0.06 & 0.14 \\
Framingham risk score, \% & 0.21 & $<0.001$ \\
FMD, \% & 0.07 & 0.09 \\
\hline
\end{tabular}

Univariate analysis of the relationship between serum triglyceride levels and variables (Pearson's correlation analysis). Abbreviations as in Table 1.

the patients were on statins, $13(2 \%)$ were on fibrates, 42 $(6 \%)$ were on eicosapentaenoic acids, and $46(7 \%)$ were on ezetimibe.

Relationships Between Serum TG Levels and CV Risk Factors Participants were categorized into 4 groups based on serum TG levels (Table 1). Body mass index, total cholesterol, sdLDL-C, ratio of sdLDL-C to LDL-C, non-HDL-C, glucose, and Framingham risk score were significantly increased and age and HDL-C were significantly decreased with an increase in serum TG level. There were significant differences in the prevalence of hypertension and prevalence of dyslipidemia among the 4 groups. There were significant relationships of serum TG levels with sdLDL-C, ratio of sdLDL-C to LDL-C, non-HDL-C, and HDL-C. Serum TG levels did not correlate with LDL-C (Table 2).

\section{Serum TG Levels and CV Events}

During a median follow-up period of 46.6 months (interquartile range, 40.9-54.6 months), 14 patients died ( 9 from CV causes), 16 had nonfatal ACS, 6 had nonfatal stroke, 54 had CAD, and 5 had hospitalization for heart failure (Table 3). The Kaplan-Meier curves for first major $\mathrm{CV}$ event among the 4 groups according to serum TG level $(\mathrm{P}=0.04$; Figure 1A) and ratio of sdLDL-C to LDL-C $(\mathrm{P}=0.02$; Supplementary Figure 1A) were significantly different, but there were no significant differences between the Kaplan-Meier curves for first major CV event among the 4 groups according to LDL-C $(\mathrm{P}=0.97$; Figure 1B $)$, HDL-C $(\mathrm{P}=0.15$; Supplementary Figure 1B), non-HDL-C $(\mathrm{P}=0.49$; Supplementary Figure $1 \mathrm{C})$, and sdLDL-C $(\mathrm{P}=0.46$; Supplementary Figure 1D). Clinical characteristics and clinical outcomes of the patients on the basis of LDL-C are summarized in Supplementary Table 1 and Supplementary Table 2. The Kaplan-Meier curves for CAD among the 4 groups were significantly different $(\mathrm{P}=0.04)$, but the KaplanMeier curves for death from $\mathrm{CV}$ disease $(\mathrm{P}=0.18)$, nonfatal ACS $(\mathrm{P}=0.06)$, nonfatal stroke $(\mathrm{P}=0.98)$, hospitalization 
Table 3. Clinical Outcomes of the Subjects on the Basis of Serum Triglyceride Levels $(\mathrm{mg} / \mathrm{dL})$

\begin{tabular}{lcccccc}
\multicolumn{1}{c}{ Variable, $\mathbf{n}(\%)$} & $\begin{array}{c}\text { Total } \\
(\mathbf{n = 6 5 2 )}\end{array}$ & $\begin{array}{c}<\mathbf{1 0 0} \\
(\mathbf{n = 2 6 4 )}\end{array}$ & $\begin{array}{c}\mathbf{1 0 0 - 1 4 9} \\
(\mathbf{n = 1 8 8}\end{array}$ & $\begin{array}{c}\mathbf{1 5 0 - 1 9 9} \\
(\mathbf{n = 1 0 4 )}\end{array}$ & $\begin{array}{c}\geq 200 \\
(\mathbf{n}=\mathbf{9 6})\end{array}$ & $\begin{array}{c}\mathbf{P} \text { value } \\
\text { for trend }\end{array}$ \\
First major cardiovascular event & $82(12.6)$ & $21(8.0)$ & $30(16.0)$ & $16(15.4)$ & $15(15.6)$ & 0.03 \\
Death from cardiovascular disease & $9(1.4)$ & $2(0.8)$ & $5(2.7)$ & $0(0)$ & $2(2.1)$ & 0.12 \\
Nonfatal acute coronary syndrome & $16(2.5)$ & $4(1.5)$ & $2(1.1)$ & $5(4.8)$ & $5(5.2)$ & 0.06 \\
Nonfatal stroke & $6(0.9)$ & $2(0.8)$ & $2(1.1)$ & $1(1.0)$ & $1(1.0)$ & 0.99 \\
Coronary artery disease & $54(8.3)$ & $13(4.9)$ & $23(12.2)$ & $10(9.6)$ & $8(8.3)$ & 0.04 \\
Hospitalization for heart failure & $5(0.8)$ & $3(1.1)$ & $0(0)$ & $1(1.0)$ & $1(1.0)$ & 0.33 \\
Death from any cause & $14(2.1)$ & $6(2.3)$ & $6(3.2)$ & $0(0)$ & $2(2.1)$ & 0.15 \\
\hline
\end{tabular}

All results are presented as number (\%). First major cardiovascular events included death from cardiovascular disease, nonfatal acute coronary syndrome, nonfatal stroke, and coronary artery disease.

A

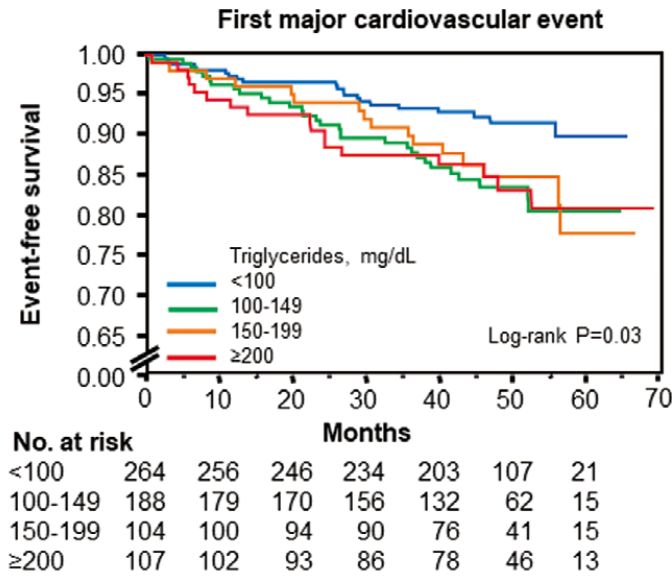

B

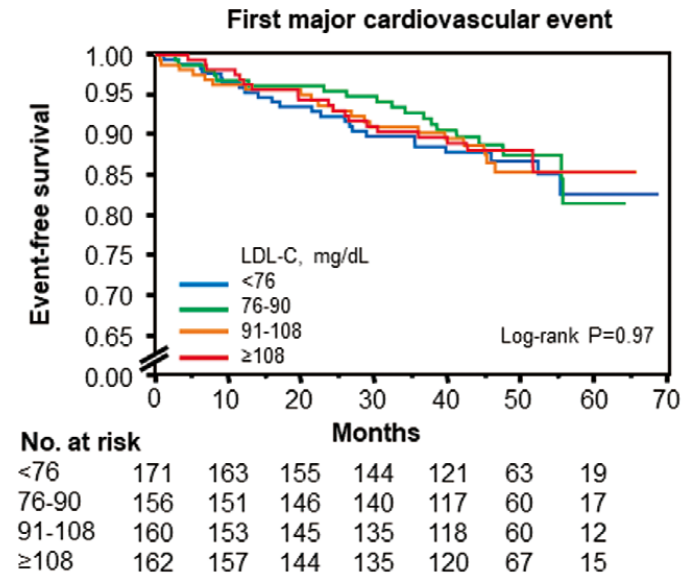

Figure 1. Kaplan-Meier curves of cumulative event-free survival of first major cardiovascular events (death from cardiovascular causes, nonfatal acute coronary syndrome, nonfatal stroke, and coronary artery disease) according to the serum triglyceride levels (A) and low-density lipoprotein cholesterol (LDL-C) (B).

for heart failure $(\mathrm{P}=0.57)$, and death from any cause $(\mathrm{P}=0.34)$ among the 4 groups according to serum TG levels were not significantly different (Figure 2, Supplementary Figure 2). Clinical outcomes of all patients on the basis of serum TG levels are shown in Table 3. After adjustment for various confounders, including LDL-C and HDL-C, serum TG levels $\geq 100 \mathrm{mg} / \mathrm{dL}$ were significantly associated with an increased risk of first major $\mathrm{CV}$ event compared with serum TG levels of $<100 \mathrm{mg} / \mathrm{dL}$ (Table 4).

\section{Discussion}

In the present study, we demonstrated that elevated serum TG levels were significantly associated with an increased risk of the incidence of first major $\mathrm{CV}$ events in patients with CAD who were treated with conventional therapy. Multivariate regression analysis revealed that even highnormal TG levels from 100 to $149 \mathrm{mg} / \mathrm{dL}$ were associated with the incidence of first major $\mathrm{CV}$ events in these patients. These findings suggest that we should pay attention to high-normal TG levels as well as to high TG levels in order to prevent CV events. Serum TG levels may be a surrogate marker for prediction of $\mathrm{CV}$ events.
Serum TG levels are associated with metabolic disorders that contribute to the pathogenesis of $\mathrm{CV}$ disease., ${ }^{\mathbf{9} 2,27} \mathrm{It}$ has been shown that serum TG levels are associated with other lipid levels, especially HDL-C., ${ }^{\mathbf{2} 2,29}$ In the present study, we confirmed that serum TG levels significantly correlated with age, body mass index, total cholesterol, HDLC, sdLDL-C, ratio of sdLDL-C to LDL-C, non-HDL-C, and glucose. In addition, the Framingham risk score increased in relation to increases in serum TG levels. In the present study, after adjustment for CV risk factors, elevated serum TG levels were significantly associated with the incidence of first major CV events in patients with CAD. These findings suggested that serum TG levels can be used to predict future $\mathrm{CV}$ events in patients with CAD.

The standard of CV risk management, especially in secondary prevention of $\mathrm{CV}$ disease, was considerably different from that in previous large-scale clinical trials. ${ }^{30}$ Most patients with $\mathrm{CV}$ disease are treated with statins, antiplatelet agents, $\beta$-blockers, diuretics, and renin-angiotensinaldosterone system inhibitors as conventional therapy. It is well known that patients with CAD have a high residual risk of $\mathrm{CV}$ events. ${ }^{3-5}$ Previous studies have shown that a high serum TG level is associated with the prevalence of 
A

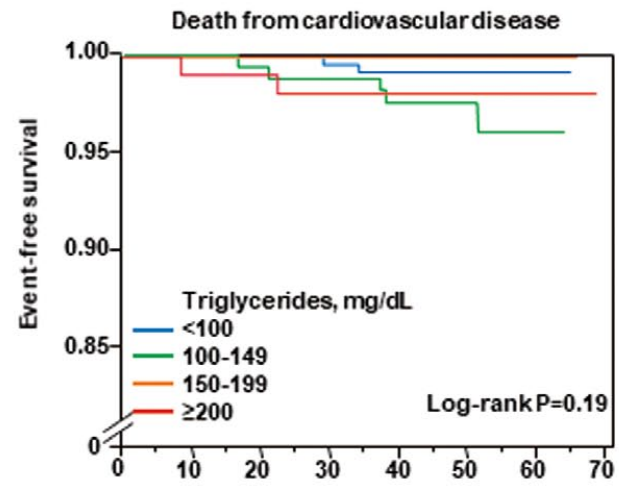

No. at risk

$\begin{array}{lllrrrrr}<100 & 264 & 261 & 254 & 247 & 217 & 114 & 22 \\ 100-149 & 188 & 186 & 181 & 173 & 150 & 73 & 19 \\ 150-199 & 104 & 103 & 99 & 98 & 85 & 49 & 17 \\ \geq 200 & 107 & 107 & 100 & 96 & 87 & 52 & 14\end{array}$

C

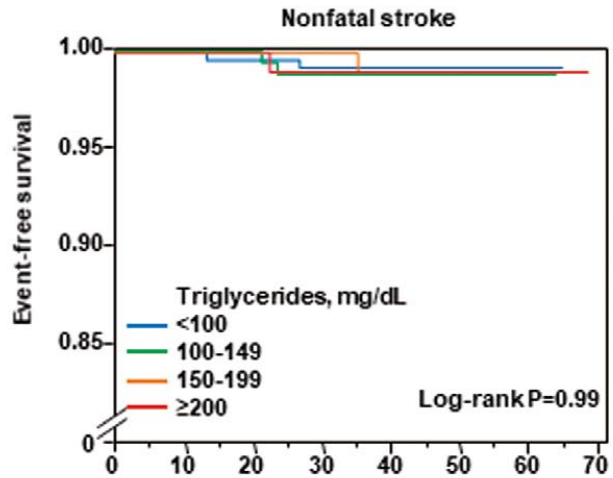

No. at risk

$<100$

100-149

150-199

$\geq 200$

E

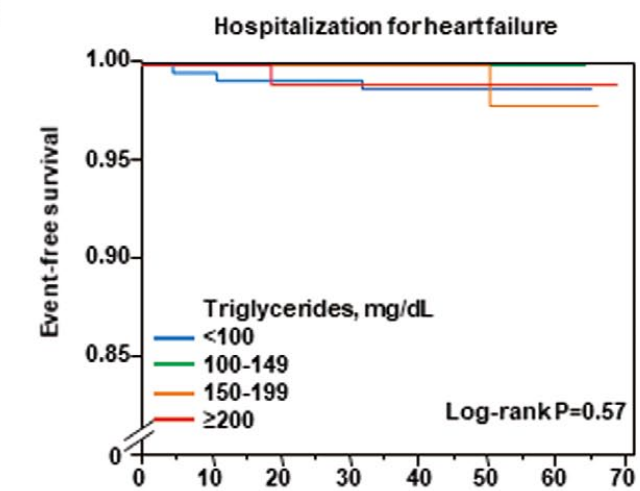

B

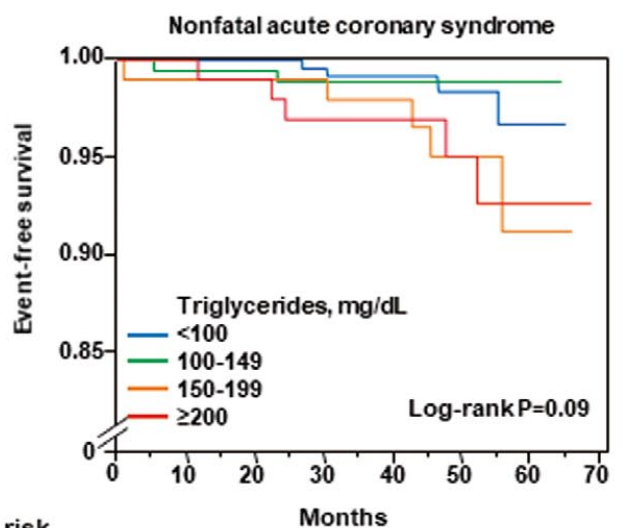

No. at risk

$\begin{array}{lrrrrrrr}<100 & 264 & 261 & 254 & 246 & 215 & 112 & 22 \\ 100-149 & 188 & 185 & 180 & 171 & 149 & 72 & 19 \\ 150-199 & 104 & 102 & 98 & 97 & 85 & 47 & 16 \\ \geq 200 & 107 & 107 & 99 & 93 & 84 & 49 & 13\end{array}$

D

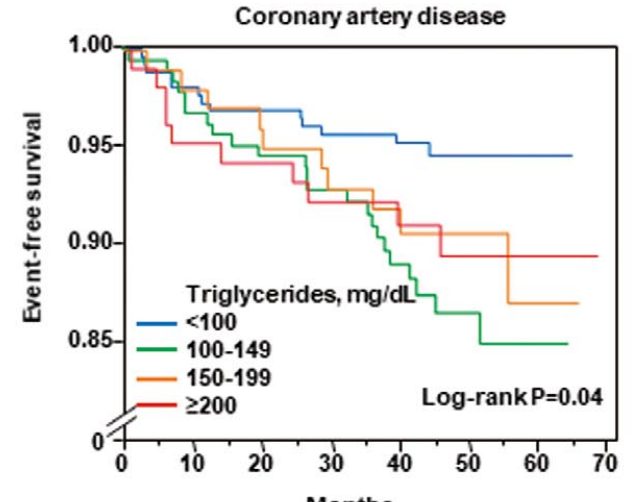

No. at risk

$<100$

$100-149$

150-199

$\geq 200$

$\begin{array}{rrrrrrr}264 & 256 & 247 & 237 & 207 & 110 & 21 \\ 188 & 180 & 171 & 160 & 133 & 63 & 15 \\ 104 & 101 & 95 & 91 & 77 & 43 & 16 \\ 107 & 102 & 94 & 89 & 81 & 49 & 14\end{array}$

$\mathbf{F}$

No. at risk

$<100$

100-149

$150-199$

$\geq 200$
Death fromany cause

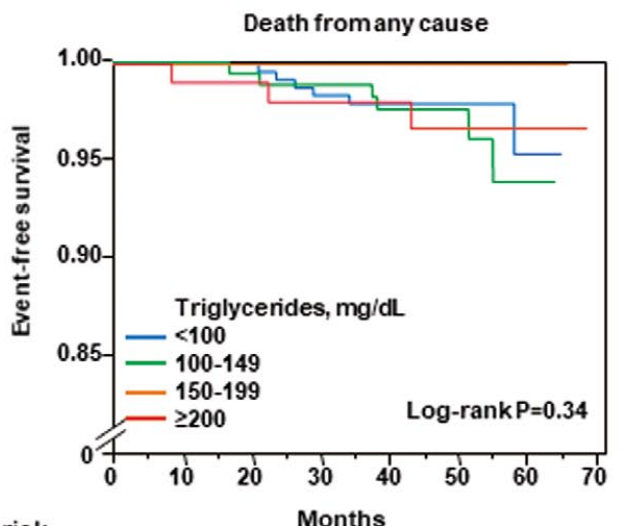

$\begin{array}{lllllll}264 & 261 & 254 & 247 & 217 & 115 & 22\end{array}$

$\begin{array}{lllllll}188 & 186 & 181 & 173 & 151 & 74 & 19\end{array}$

$\begin{array}{lllllll}104 & 103 & 99 & 98 & 85 & 49 & 17\end{array}$

$\begin{array}{lllllll}107 & 107 & 100 & 96 & 87 & 52 & 14\end{array}$

Figure 2. Kaplan-Meier curves of cumulative event-free survival of death from cardiovascular causes (A), nonfatal acute coronary syndrome $(\mathbf{B})$, nonfatal stroke $(\mathbf{C})$, coronary artery disease $(\mathbf{D})$, hospitalization for heart failure $(\mathbf{E})$, and death from any cause $(\mathbf{F})$, according to the serum triglyceride levels. 


\begin{tabular}{|c|c|c|c|c|c|c|c|}
\hline $\begin{array}{c}\text { Variable } \\
\text { Triglycerides, } \\
\text { mg/dL }\end{array}$ & $\begin{array}{c}\text { Unadjusted } \\
\text { HR (95\% Cl) } \\
\text { P value }\end{array}$ & $\begin{array}{c}\text { Adjusted }^{*} \\
\text { HR (95\% Cl) } \\
\text { P value }\end{array}$ & $\begin{array}{c}\text { Adjusted }{ }^{\prime} \\
\text { HR (95\% CI) } \\
\text { P value }\end{array}$ & $\begin{array}{c}\text { Adjusted } ¥ \\
\text { HR (95\% CI) } \\
\text { P value }\end{array}$ & $\begin{array}{l}\text { Adjusted } \$ \\
\text { HR (95\% Cl) } \\
\text { P value }\end{array}$ & $\begin{array}{l}\text { Adjustedll } \\
\text { HR (95\% CI) } \\
\text { P value }\end{array}$ & $\begin{array}{l}\text { Adjusted } \\
\text { HR (95\% Cl) } \\
\text { P value }\end{array}$ \\
\hline$<100$ & 1 (Ref.) & 1 (Ref.) & 1 (Ref.) & 1 (Ref.) & 1 (Ref.) & 1 (Ref.) & 1 (Ref.) \\
\hline \multirow[t]{2}{*}{$100-149$} & $2.12(1.22-3.75)$ & $2.18(1.26-3.86)$ & $2.11(1.19-3.83)$ & $2.07(1.14-3.83)$ & $2.07(1.14-3.75)$ & $2.01(1.09-3.69)$ & $2.08(1.13-3.80)$ \\
\hline & 0.008 & 0.006 & 0.01 & 0.02 & 0.02 & 0.02 & 0.02 \\
\hline \multirow[t]{2}{*}{$150-199$} & $1.96(1.01-3.74)$ & $2.09(1.07-4.00)$ & $2.25(1.12-4.44)$ & $2.17(1.07-4.34)$ & $2.32(1.14-4.70)$ & $2.25(1.06-4.76)$ & $2.22(1.11-4.45)$ \\
\hline & 0.04 & 0.03 & 0.02 & 0.03 & 0.02 & 0.04 & 0.02 \\
\hline \multirow[t]{2}{*}{$\geq 200$} & $2.04(1.05-3.95)$ & $2.25(1.15-4.41)$ & $2.38(1.18-4.78)$ & $2.36(1.14-4.91)$ & $2.50(1.23-5.07)$ & $2.38(1.04-5.43)$ & $2.32(1.12-4.84)$ \\
\hline & 0.04 & 0.02 & 0.02 & 0.02 & 0.01 & 0.04 & 0.02 \\
\hline
\end{tabular}

${ }^{*}$ Adjusted for age, sex. ${ }^{\dagger}$ Adjusted for age, sex, BMI, SBP, LDL-C, glucose and current smoking. ${ }^{\ddagger}$ Adjusted for age, sex, BMI, SBP, HDL-C, glucose and current smoking. §Adjusted for age, sex, BMI, SBP, LDL-C, glucose, current smoking, FMD, and high-sensitivity CRP. "Adjusted for age, sex, BMI, SBP, small dense LDL-C, glucose and current smoking. ^Adjusted for age, sex, BMI, SBP, LDL-C, HDL-C, glucose and current smoking. $\mathrm{Cl}$, confidence interval; HR, hazard ratio. Other abbreviations as in Table 1.

$\mathrm{CV}$ events in patients with low LDL-C but not in those with high LDL-C. ${ }^{10,31}$ In addition, a previous study showed that serum TG levels predict both long-term and shortterm CV risk in patients with ACS who are treated with statins. ${ }^{32}$ Interestingly, Miller et al showed that the combination of LDL-C level $<70 \mathrm{mg} / \mathrm{dL}$ and TG level $<150 \mathrm{mg} / \mathrm{dL}$ was associated with a low risk of $\mathrm{CV}$ events compared with LDL-C level $\geq 70 \mathrm{mg} / \mathrm{dL}$, TG level $\geq 150 \mathrm{mg} / \mathrm{dL}$, or both. ${ }^{33}$ These findings suggest that lowering TGs with control of LDL-C may be effective to reduce future $\mathrm{CV}$ events. In the present study, $88 \%$ of the patients received lipid-lowering therapy and had a mean LDL-C value of $93 \mathrm{mg} / \mathrm{dL}$. We confirmed that elevated serum TG levels were significantly associated with first $\mathrm{CV}$ events in patients with $\mathrm{CAD}$ who received conventional therapy. Management of serum TG levels is recommended in patients with CAD. As exploratory analysis in a subgroup, we evaluated the association between serum TG levels and first CV events in patients with strictly controlled LDL-C levels. In that study, 110 of the 652 patients had LDL-C levels $<70 \mathrm{mg} / \mathrm{dL}$. We categorized patients into 2 groups according to the median serum TG level: a low group $(<113 \mathrm{mg} / \mathrm{dL})$ and a high group $(\geq 113 \mathrm{mg} / \mathrm{dL})$. First major $\mathrm{CV}$ events occurred in 17 patients. There was no significant difference between the Kaplan-Meier curves for first major $\mathrm{CV}$ events $(\mathrm{P}=0.17$; Supplementary Figure 3). Further studies are required to confirm the relationship between serum TG levels and first $\mathrm{CV}$ events in patients with strictly controlled LDL-C levels.

Several lines of evidence have shown an independent association between elevated serum TG levels and CV events. ${ }^{5-10}$ Studies have shown that fibrates reduce the incidence of $\mathrm{CV}$ events in a subgroup of patients with elevated TGs. ${ }^{13,14,34,35}$ Unfortunately, there is insufficient evidence available to determine optimal TG levels in order to prevent $\mathrm{CV}$ events. ${ }^{2,9} \mathrm{~A}$ scientific statement by the American Heart Association suggested that the optimal serum TG level may be $<100 \mathrm{mg} / \mathrm{dL} .{ }^{9}$ Recently, we have shown that endothelial function is already impaired in subjects with serum TG levels of $106-131 \mathrm{mg} / \mathrm{dL}$ after adjustment of various confounders including HDL-C. ${ }^{16}$ In the present study, the prevalence of first major $\mathrm{CV}$ events was significantly higher in patients with serum TG levels $\geq 100 \mathrm{mg} / \mathrm{dL}$ than in patients with serum TG levels $<100 \mathrm{mg} / \mathrm{dL}$. The results of our study indicated a significant association between serum TG levels $\geq 100 \mathrm{mg} / \mathrm{dL}$ and residual risk in patients with CAD who are receiving conventional therapy. Future studies in a large population are needed to confirm the optimal target level of TGs for prevention of CV events and to determine whether lowering TG levels to the optimal target level reduces $\mathrm{CV}$ events.

\section{Study Limitations}

First, we measured serum TG levels only once when the patients were enrolled. Repeated measurements of serum TG may be more useful as a surrogate marker of future CV events. Second, in the present study, serum levels of LDL-C were not associated with the incidence of first major CV events. There are some possible reasons for this result. The prevalence of dyslipidemia and the level of glucose were significantly higher in patients with LDL-C levels $<76 \mathrm{mg} / \mathrm{dL}$ (Supplementary Table 1). These CV risk factors may affect the relationship between LDL-C and the risk of CV events. We previously reported that endothelial function was significantly correlated with levels of LDL-C in subjects not receiving statin therapy but not in subjects receiving statin therapy. ${ }^{36}$ In the present study, more than $80 \%$ of the patients in the study groups were on statin therapy. We cannot deny the possibility that cholesterol-lowering therapy using statins hinders the effects of raw values of LDL-C on $\mathrm{CV}$ events.

In conclusion, a serum TG level $\geq 100 \mathrm{mg} / \mathrm{dL}$ was independently associated with the incidence of $\mathrm{CV}$ events in patients with CAD. Levels of TGs should be considered more seriously as a future target to reduce CV events.

\section{Acknowledgments}

We thank Megumi Wakisaka, Kiichiro Kawano, and Satoko Michiyama for their excellent assistance with the manuscript.

\section{Sources of Funding}

This study was supported in part by a Grant in Aid of Japanese Atherosclerosis Prevention Fund.

\section{Disclosures}

None.

\section{Clinical Trial Registration Information}

URL for Clinical Trial: http://UMIN; Registration Number for Clinical Trial: UMIN000012950

\section{References}

1. Kinoshita M, Yokote K, Arai H, Iida M, Ishigaki Y, Ishibashi $\mathrm{S}$, et al. Japan Atherosclerosis Society (JAS) Guidelines for Prevention of Atherosclerotic Cardiovascular Diseases 2017. J Ath- 
eroscler Thromb 2018; 25: 846-984.

2. National Cholesterol Education Program (NCEP) Expert Panel on Detection, Evaluation, and Treatment of High Blood Cholesterol in Adults (Adult Treatment Panel III). Third Report of the National Cholesterol Education Program (NCEP) Expert Panel on Detection, Evaluation, and Treatment of High Blood Cholesterol in Adults (Adult Treatment Panel III) final report. Circulation 2002; 106: 3143 - 3421.

3. Stone NJ, Robinson JG, Lichtenstein AH, Bairey Merz CN, Blum $\mathrm{CB}$, Eckel RH, et al; American College of Cardiology/American Heart Association Task Force on Practice Guidelines. 2013 ACC/ AHA guideline on the treatment of blood cholesterol to reduce atherosclerotic cardiovascular risk in adults: A report of the American College of Cardiology/American Heart Association Task Force on Practice Guidelines. Circulation 2014; 129(Suppl 2): $\mathrm{S} 1-\mathrm{S} 45$

4. Catapano AL, Graham I, De Backer G, Wiklund O, Chapman MJ, Drexel H, et al; Authors/Task Force Members; Additional Contributor. 2016 ESC/EAS guidelines for the management of dyslipidaemias. Eur Heart J 2016; 37: 2999-3058.

5. Reiner Ž. Hypertriglyceridaemia and risk of coronary artery disease. Nat Rev Cardiol 2017; 14: 401-411.

6. Nordestgaard BG, Varbo A. Triglycerides and cardiovascular disease. Lancet 2014; 384: 626-635.

7. Do R, Willer CJ, Schmidt EM, Sengupta S, Gao C, Peloso GM, et al. Common variants associated with plasma triglycerides and risk for coronary artery disease. Nat Genet 2013; 45: 1345-1352.

8. Sarwar N, Danesh J, Eiriksdottir G, Sigurdsson G, Wareham N, Bingham S, et al. Triglycerides and the risk of coronary heart disease: 10,158 incident cases among 262,525 participants in 29 Western prospective studies. Circulation 2007; 115: 450-458.

9. Miller M, Stone NJ, Ballantyne C, Bittner V, Criqui MH, Ginsberg $\mathrm{HN}$, et al. Triglycerides and cardiovascular disease: A scientific statement from the American Heart Association. Circulation 2011; 123: $2292-2333$.

10. Criqui MH, Heiss G, Cohn R, Cowan LD, Suchindran CM, Bangdiwala $S$, et al. Plasma triglyceride level and mortality from coronary heart disease. $N$ Engl J Med 1993; 328: 1220-1225.

11. Emerging Risk Factors Collaboration, Di Angelantonio E, Sarwar N, Perry P, Kaptoge S, Ray KK, Thompson A, et al. Major lipids, apolipoproteins, and risk of vascular disease. JAMA 2009; 302: $1993-2000$

12. Schwartz GG, Olsson AG, Szarek M, Sasiela WJ. Relation of characteristics of metabolic syndrome to short-term prognosis and effects of intensive statin therapy after acute coronary syndrome: An analysis of the Myocardial Ischemia Reduction with Aggressive Cholesterol Lowering (MIRACL) trial. Diabetes Care 2005; 28: $2508-2513$.

13. Lee M, Saver JL, Towfighi A, Chow J, Ovbiagele B. Efficacy of fibrates for cardiovascular risk reduction in persons with atherogenic dyslipidemia: A meta-analysis. Atherosclerosis 2011; 217: $492-498$.

14. ACCORD Study Group, Ginsberg HN, Elam MB, Lovato LC, Crouse JR 3rd, Leiter LA, Linz P, et al. Effects of combination lipid therapy in type 2 diabetes mellitus. N Engl J Med 2010; 362: $1563-1574$

15. Klempfner R, Erez A, Sagit BZ, Goldenberg I, Fisman E, Kopel $\mathrm{E}$, et al. Elevated triglyceride level is independently associated with increased all-cause mortality in patients with established coronary heart disease: Twenty-two-year follow-up of the bezafibrate infarction prevention study and registry. Circ Cardiovasc Qual Outcomes 2016; 9: 100-108.

16. Kajikawa M, Maruhashi T, Matsumoto T, Iwamoto Y, Iwamoto A, Oda N, et al. Relationship between serum triglyceride levels and endothelial function in a large community-based study. Atherosclerosis 2016; 249: 70-75.

17. Tomiyama H, Kohro T, Higashi Y, Takase B, Suzuki T, Ishizu $\mathrm{T}$, et al. A multicenter study design to assess the clinical usefulness of semi-automatic measurement of flow-mediated vasodilatation of the brachial artery. Int Heart J 2012; 53: 170-175.

18. Maruhashi T, Soga J, Fujimura N, Idei N, Mikami S, Iwamoto $\mathrm{Y}$, et al. Endothelial dysfunction, increased arterial stiffness, and cardiovascular risk prediction in patients with coronary artery disease: FMD-J (Flow-Mediated Dilation Japan) Study A. J Am Heart Assoc 2018; 7: e008588.

19. Teramoto T, Sasaki J, Ishibashi S, Birou S, Daida H, Dohi S, et al. Treatment B) drug therapy: Executive summary of the Japan Atherosclerosis Society (JAS) guidelines for the diagnosis and prevention of atherosclerotic cardiovascular diseases in Japan: 2012 version. $J$ Atheroscler Thromb 2013; 20: 850-860.

20. Shimamoto K, Ando K, Fujita T, Hasebe N, Higaki J, Horiuchi $\mathrm{M}$, et al; Japanese Society of Hypertension Committee for Guidelines for the Management of Hypertension. The Japanese Society of Hypertension Guidelines for the management of hypertension (JSH 2014). Hypertens Res 2014; 37: 253-390.

21. Haneda M, Noda M, Origasa H, Noto H, Yabe D, Fujita Y, et al. Japanese clinical practice guideline for diabetes 2016. J Diabetes Investig, doi:10.1111/jdi.12810.

22. Ito Y, Fujimura M, Ohta M, Hirano T. Development of a homogeneous assay for measurement of small dense LDL cholesterol. Clin Chem 2011; 57: 57-65.

23. American Diabetes Association. 2. Classification and diagnosis of diabetes. Diabetes Care 2017; 40(Suppl 1): S11-S24.

24. Wilson PW, Castelli WP, Kannel WB. Coronary risk prediction in adults (the Framingham Heart Study). Am J Cardiol 1987; 59: 91G-94G

25. Kajikawa M, Maruhashi T, Hida E, Iwamoto Y, Matsumoto T, Iwamoto A, et al. A combination of FMD and nitroglycerineinduced vasodilation is more effective for prediction of cardiovascular events. Hypertension 2016; 67: 1045-1052.

26. Bansal S, Buring JE, Rifai N, Mora S, Sacks FM, Ridker PM. Fasting compared with nonfasting triglycerides and risk of cardiovascular events in women. JAMA 2007; 298: 309-316.

27. West KM, Ahuja MM, Bennett PH, Czyzyk A, De Acosta OM, Fuller JH, et al. The role of circulating glucose and triglyceride concentrations and their interactions with other "risk factors" as determinants of arterial disease in nine diabetic population samples from the WHO multinational study. Diabetes Care 1983; 6: 361-369.

28. Bitzur R, Cohen H, Kamari Y, Shaish A, Harats D. Triglycerides and HDL cholesterol: Stars or second leads in diabetes? Diabetes Care 2009; 32(Suppl 2): S373-S377.

29. Chapman MJ, Ginsberg HN, Amarenco P, Andreotti F, Borén J, Catapano AL, et al. Triglyceride-rich lipoproteins and high-density lipoprotein cholesterol in patients at high risk of cardiovascular disease: Evidence and guidance for management. Eur Heart $J$ 2011; 32: 1345-1361.

30. Record NB, Onion DK, Prior RE, Dixon DC, Record SS, Fowler $\mathrm{FL}$, et al. Community-wide cardiovascular disease prevention programs and health outcomes in a rural county, 1970-2010. JAMA 2015; 313: 147-155.

31. Liu J, Wang W, Wang M, Sun J, Liu J, Li Y, et al. Impact of diabetes, high triglycerides and low HDL cholesterol on risk for ischemic cardiovascular disease varies by LDL cholesterol level: A 15-year follow-up of the Chinese Multi-provincial Cohort Study. Diabetes Res Clin Pract 2012; 96: 217-224.

32. Schwartz GG, Abt M, Bao W, DeMicco D, Kallend D, Miller $\mathrm{M}$, et al. Fasting triglycerides predict recurrent ischemic events in patients with acute coronary syndrome treated with statins. $J$ Am Coll Cardiol 2015; 65: 2267-2275.

33. Miller M, Cannon CP, Murphy SA, Qin J, Ray KK, Braunwald E; PROVE IT-TIMI 22 Investigators. Impact of triglyceride levels beyond low-density lipoprotein cholesterol after acute coronary syndrome in the PROVE IT-TIMI 22 trial. $J$ Am Coll Cardiol 2008; 51: 724-730.

34. Jun M, Foote C, Lv J, Neal B, Patel A, Nicholls SJ, et al. Effects of fibrates on cardiovascular outcomes: A systematic review and meta-analysis. Lancet 2010; 375: 1875-1884.

35. Bezafibrate Infarction Prevention (BIP) study. Secondary prevention by raising HDL cholesterol and reducing triglycerides in patients with coronary artery disease. Circulation 2000; 102: 21 27.

36. Matsui S, Kajikawa M, Hida E, Maruhashi T, Iwamoto Y, Iwamoto A, et al. Optimal target level of low-density lipoprotein cholesterol for vascular function in statin naïve individuals. Sci Rep 2017; 7: 8422 .

\section{Supplementary Files}

Please find supplementary file(s); http://dx.doi.org/10.1253/circj.CJ-18-1082 